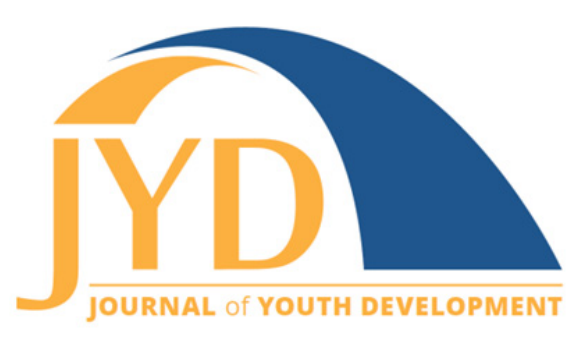

http://jyd.pitt.edu/ | Vol. 12 Issue 3 DOI 10.5195/jyd.2017.508 | ISSN 2325-4017 (online)

\title{
"It's more like we want to come to this": Program Engagement in a Sexual Health Youth Leadership Council
}

\author{
Christyl Yensuahte-Ardina Wilson* \\ Georgia State University \\ cwilson60@gsu.edu \\ Scot Seitz* \\ Georgia State University \\ sseitz3@student.gsu.edu \\ Kimberly Broomfield-Massey \\ Emstar Research, Inc. \\ kbroomfieldmassey1@gmail.com \\ Lucy Whitehead \\ Georgia State University \\ lewhitehead1@gmail.edu \\ Julia Mangia \\ Georgia State University \\ juliamangia2014@gmail.com \\ Keri McDonald Pridgeon \\ The Center for Black Women's Wellness \\ kpridgeon@cbww.org \\ Gabriel Kuperminc \\ Georgia State University \\ gkuperminc@gsu.edu
}

*These authors contributed equally to this manuscript.

\section{Abstract}

Participants in the Looking Out for the Youth (L.O.F.T.Y) Crew, a sexual-health youth leadership council, reported and exhibited high engagement within the program. Understanding program characteristics that contribute to engagement is important because engagement is associated with positive outcomes for youth and program sustainability. According to self-determination theory (Ryan \& Deci, 2000), programs that meet youth's needs for autonomy, relatedness, and competence are more likely to facilitate sustained engagement. This qualitative study examined

\footnotetext{
(cc) $\mathbf{E Y}$ New articles in this journal are licensed under a Creative Commons Attribution 4.0 License. This journal is published by the University Library System, University of Pittsburgh and is cosponsored by the University of Pittsburgh Press. The Journal of Youth Development is the official peer-reviewed publication of the National Association of Extension 4-H Agents and the National AfterSchool Association.
} 


\section{Engagement in a Youth Leadership Council}

youth perceptions about the components of the program that contributed to engagement. We conducted focus group and interviews with L.O.F.T.Y Crew participants ( $N=42)$. With selfdetermination theory as a framework, we analyzed the data using a directed content analysis approach. Our analyses yielded five themes related to program engagement: ownership, youth voice, meaningful peer connection, adults as mentors, and increased knowledge and skills. Overall, the results provide support for self-determination theory. Importantly, by identifying specific action steps that can be implemented to increase youth engagement, this qualitative study can help practitioners translate theory to action.

Key words: engagement, youth leadership council, sexual health, self-determination theory

\section{Introduction}

Youth leadership councils (YLCS) have been included as a component of some sexual health interventions as a way to encourage adolescents to promote sexual health in their communities (e.g., Sikkema et al., 2005). YLCs draw on youth's community expertise to organize and implement a variety of program activities (Matthews, 2001). The current study focuses on "Looking Out For The Youth" (L.O.F.T.Y.) Crew, a sexual health-focused YLC. From 2011 until 2015, L.O.F.T.Y. Crew organized youth-centered, community-wide activities including health fairs, HIV testing drives, a short film that premiered at a local museum, and a public service announcement that was aired on a local television station and in local movie theaters.

Throughout implementation, it was common for participants to describe L.O.F.T.Y. Crew as highly engaging. When surveyed, L.O.F.T.Y. Crew participants $(N=48)$ reported an average score of 3.9 out of 4 on a 3-question engagement scale (Felmet, 2014). This level of engagement is impressive, as some youth programs have trouble garnering sustained youth engagement and attendance (Matthews, 2001). The purpose of this qualitative study was to identify specific aspects of the program that participants experienced as engaging and contributing to their sustained participation.

\section{Program Engagement}

Program engagement can be defined as active participation which includes "high attention, interest, enjoyment, and effort to master new skills" (Bohnert, Fredricks, \& Randall, 2010, p. 593). This level of participation is associated with many positive outcomes (reviewed in Bohnert et al., 2010). For example, previous studies have found that program engagement was associated with social competence, intrinsic motivation to solve problems, and academic achievement (Mahoney, Parente, \& Lord, 2007; Shernoff, 2010). However, there is a lack of 


\section{Engagement in a Youth Leadership Council}

research on specific components of YLCs that facilitate participant engagement. In fact, to our knowledge this is the first study to examine youth's engagement in a YLC that is focused on sexual health promotion.

\section{Engagement and Self-Determination Theory}

Self-determination theory is one promising model for understanding program engagement. According to self-determination theory (Ryan \& Deci, 2000), youth are most likely to be engaged and to adopt program goals when the program fulfills three psychological needs: autonomy, relatedness, and competence. Autonomy denotes a sense of agency in designing and carrying out program activities. Relatedness refers to connections with other people in the program. Competence reflects a sense of efficacy with respect to performing behaviors within the program (e.g., public speaking, organizing health fairs).

Research has found that satisfaction of the three psychological needs is associated with increased engagement and retention in youth programs. For example, based on questionnaire data from adolescents in physical education classes, needs fulfillment predicted motivation and increased intentions to participate in optional physical education classes (Ntoumanis, 2005). In another study, researchers found that relatedness, autonomy, and competence interacted to create an enjoyable program atmosphere; program participants experienced competence and relatedness when staff members taught new skills and the participants felt autonomous when given the freedom to learn at their own pace (Ward \& Parker, 2013).

The current study used self-determination theory as a framework to explore characteristics of a YLC that contribute to participant engagement. By identifying program characteristics that facilitate autonomy, relatedness, and competence, we hope to help other practitioners design programs that engage youth and increase program retention.

\section{L.O.F.T.Y. Crew}

L.O.F.T.Y. Crew is the YLC component of a broader community-level sexual health program called the Teen Health Project (Sikkema et al., 2005). With guidance from health educators, L.O.F.T.Y. Crew members worked together to host community-wide events that provide sexual health information to promote safe sexual behavior, such as abstinence, regular condom use, and routine HIV testing. 


\section{Engagement in a Youth Leadership Council}

\section{Method}

This study was part of a larger evaluation of the Teen Health Project, and was approved by the Institutional Review Board at a large research university. Former and current L.O.F.T.Y. Crew members who participated in the four cohorts from 2012 to 2015 were invited to participate in the study by the health educators via email and/or in person. After obtaining informed consent from adult participants and parents of minors, the focus groups and interviews were conducted at program implementation sites. The first, second, and/or third author conducted the focus groups and interviews. These three authors did not implement any Teen Health Project programming, so their participation was not expected to influence the data collected.

A semi-structured protocol was followed for each focus group and interview, which allowed for relevant follow-up questions when appropriate. The semi-structured protocol included questions that addressed the following domains: description of L.O.F.T.Y. Crew activities, aspects of the program that were enjoyed most/least, knowledge and skills required to implement L.O.F.T.Y. Crew activities, knowledge and skills gained from participating in the program, level of personal connection with L.O.F.T.Y. Crew peers and health educators, participants' involvement in decision making about program activities, individual changes noticed after participating in L.O.F.T.Y. Crew, and recommendations for improving L.O.F.T.Y. Crew. Each participant received a $\$ 10$ gift card. All focus groups and interviews were audio-recorded and transcribed verbatim, excluding identifying information.

\section{Participants}

Forty-two L.O.F.T.Y. Crew members and alumni participated in the study, representing 53\% of all members in the four L.O.F.T.Y. Crew cohorts from 2012 to 2015. All the participants identified as African American except for one participant who identified as Other. Sixty-two percent of the participants were female, and the average age was 17 years old (ranging from 15 to 21 years old).

\section{Data Collection}

A total of four focus groups and two interviews were conducted with an average of 10 participants in each focus group. Focus groups were the preferred method of data collection because they allowed researchers to observe youth interactions, providing insight into how the youth may have interacted with each other during their participation in the L.O.F.T.Y. Crew 


\section{Engagement in a Youth Leadership Council}

program. Two individual interviews were conducted to accommodate participants who were not able to attend the focus groups due to scheduling conflicts.

During all focus groups, participants were actively engaged (e.g., contributing perspectives, collaboratively constructing a narrative, actively listening). This high level of engagement was consistent with the anecdotes that inspired this study.

\section{Qualitative Data Analysis}

We analyzed the interviews using a directed content analysis approach (Hsieh \& Shannon, 2005). This deductive approach was appropriate because it allowed the researchers to use an existing framework (self-determination theory) to construct meaning from L.O.F.T.Y Crew participants' experiences.

The first, third, and fourth authors coded the data. Two of these coders have formal training in qualitative methods and have previously conducted qualitative data analysis. During initial coding, the coders reviewed the transcripts and identified all potential codes that were relevant to youth development and aspects of L.O.F.T.Y. Crew that may have contributed to engagement. These codes were discussed and organized in a codebook. Once the codebook was finalized, two of the research staff members coded each transcript. The overall percent agreement among the coders was $71 \%$. The coding team discussed all coding discrepancies to determine final codes. Finally, the authors reviewed the coded qualitative data and thematically grouped codes. Microsoft Excel (2013) was used to compile, organize, and analyze the qualitative data.

\section{Results}

Our analyses yielded five themes related to program engagement: ownership, youth voice, meaningful peer connection, adults as mentors, and increased knowledge and skills. We organized these themes based on their correspondence to the components of autonomy, relatedness, and competence that are central to self-determination theory. 


\section{Engagement in a Youth Leadership Council}

\section{Autonomy}

As the participants described their involvement in L.O.F.T.Y. Crew, they often highlighted their ability to have a say in program activities. Two themes related to the overarching construct of autonomy included ownership and youth voice.

Ownership: "Everything was our idea. Nothing was prior planned."L.O.F.T.Y. Crew participants shared that they enjoyed the freedom they experienced while serving on the council. The structure of L.O.F.T.Y. Crew allowed for a sense of autonomy because youth were essentially in charge of the council. While there are general guidelines for L.O.F.T.Y. Crew (e.g., weekly meetings, health educator facilitation, the overall theme of sexual health promotion), there is no predetermined curriculum.

Each cohort generated new ideas and, with support from health educators, implemented their ideas throughout their tenure in the council. Participants expressed enthusiasm about this feature of the program. In response to a question about what they enjoyed most about being in L.O.F.T.Y. Crew, one participant stated, "What I enjoyed most? Putting on the events. Especially when we had to plan things. Everything was our idea. Nothing was prior planned."

Youth voice: "I felt like my opinion mattered. Everyone's did."By providing a space for autonomy, the youth council gave participants a voice. Several participants shared that they felt validated when their opinions were heard. One focus group illustrated this process by providing an example of the time they were planning a public service announcement (PSA). They explained that they first voted on the PSA's central message. Then, all council members had an opportunity to share their ideas for the script. These ideas were then written on a classroom board, followed by a group discussion that led to a consensus.

Students were collectively empowered throughout this process, as one student shared, "I felt like my opinion mattered. Everyone's did." Another participant felt like she gained confidence as a result of sharing her opinions. She stated, "I feel more open to talk now, at first I wasn't...if we was in a group discussion right now I wouldn't be able to just really voice my opinion but I feel like being in L.O.F.T.Y. Crew I was able to voice my opinion around my peers." Several focus group participants shared that nobody's ideas were ever "shot down" in L.O.F.T.Y. Crew. Rather, everyone was encouraged to share, and the group had a constructive discussion before deciding on a final decision. 


\section{Engagement in a Youth Leadership Council}

\section{Relatedness}

Most L.O.F.T.Y. Crew participants expressed that they built significant relationships with their peers and the health educators. They also described specific aspects of the program that seemed to facilitate the development of these relationships. The two themes relevant to relatedness were meaningful peer connection and adults as mentors.

Meaningful peer connection: "You talk to specific people outside but when you get in here, the wall breaks down. "Participants cited L.O.F.T.Y. Crew meetings as a safe space where they could build meaningful relationships with people who are not part of their typical peer groups or cliques. L.O.F.T.Y. Crew was comprised of youth from different peer groups with varying interests. One member stated that, compared to other extra-curricular activities, L.O.F.T.Y. Crew

was unique... because most of the other time it be like a sport or dancin' you have to be particularly good at so y'all end up being particularly similar. L.O.F.T.Y. Crew is different. Only thing that we all shared was the interest in L.O.F.T.Y. Crew. So it was kinda better for everybody to gel together to meet somebody from different viewpoints.

Additionally, youth regularly engaged in facilitated conversations and activities about sensitive topics like safe sex practices. The youth indicated that these conversations helped them build deeper, more meaningful relationships because they were facilitated in a safe space where each member felt comfortable sharing their opinions and disclosing personal information. For example, one participant said, "Not everyone has people to go to when they wanna know information or to guide them through certain life situations...so to have like a group where we can come to each other if we don't have someone to talk to...it was a good thing."

Finally, each cohort participated in teambuilding activities (e.g., ropes courses) and was responsible for planning and hosting various events, which required teamwork. The youth noted that working as a team helped them to not only organize and execute successful events, but also to create trusting relationships with each other.

Adults as mentors: "They were more like our friends than our teachers at school. "Across all focus groups and interviews, participants expressed that they were also able to build close personal relationships with the L.O.F.T.Y. Crew health educators in a way that was different 


\section{Engagement in a Youth Leadership Council}

than with other adults in their lives. They shared that the health educators facilitated open conversations and answered any questions that the youth may not have been able to ask at home or in class. One participant noted, "... I feel that [the health educators] did a great job as far as making me feel that I can come to them and talk to them about anything that I need... It wasn't like a judgmental...vibe, they made me feel open and accepted."

Health educators interacted with youth in a way that was less formal than regular teachers. One participant described the health educators as "...relatable; they understood and they weren't in a total adult type mindset as far as interacting with us. They were able to get down on our level and be 100 with us." The youth also noted that they remained connected to the program because they could engage in open, non-judgmental conversations with the health educators. As one participant said, "We can look forward to something and talking like this. Normally you would think it's boring or something but the people that's teaching the class, they cool...It's more like we want to come to this" [emphasis added].

\section{Competence}

Participants often expressed feeling competent in their abilities to organize and implement L.O.F.T.Y. Crew activities. Specifically, participants stated that the program provided them with the background knowledge and practice necessary to successfully plan and implement the activities. Participants also noted that they felt competent in their abilities to promote sexual health practices beyond the scope of the council's activities. The theme in the data that captured the competence dimension was labeled increased knowledge and skills.

Increased knowledge and skills: "I feel more prepared to talk about this kinda stuff [sexual risk reduction], like I can make a difference among my peers. "Through participation in L.O.F.T.Y. Crew, the youth received training in local HIV/STD statistics, public speaking, and community outreach methods. During these training sessions, they learned how to succinctly deliver a message, engage with people in individual and group settings, and identify and respond to body language. Youth also had opportunities to role-play and practice delivering risk reduction messages at council meetings; they then applied this knowledge in real-world settings as they worked to promote sexual risk reduction in their community.

Youth described developing a sense of competence through the process of collaboratively planning activities, researching the information that would be presented during community events, and role-playing prior to engaging in the events. The knowledge and the skills learned 


\section{Engagement in a Youth Leadership Council}

in L.O.F.T.Y. resulted in youth who felt prepared to effectively carry out the goals of the council. As one L.O.F.T.Y. Crew member stated "... I feel more prepared to talk about this kinda stuff, like I can make a difference among my peers." Another stated "I feel like I know what I'm talking about. I feel like I don't have to guess or think in the back of my head."

\section{Discussion}

The goal of this study was to explore how a sexual health YLC promoted participant engagement by supporting the three psychological needs described in self-determination theory: autonomy, relatedness, and competence (Ryan \& Deci, 2000). According to this theory, needs fulfillment is correlated with youth engagement. Engagement is an important goal because it is associated with positive youth outcomes, such as social competence and academic achievement (Bohnert et al., 2010).

In this study, the participants reported that their ideas were respected in the L.O.F.T.Y. Crew program and that they were free to act on their ideas. The program facilitated this sense of autonomy by encouraging the participants to discuss their ideas as a group and then vote to determine the final decisions. Researchers have previously demonstrated that allowing participants to design the structure and activities of youth programs can create a positive atmosphere, increase enjoyment in the program, and lead to greater program engagement (Ward \& Parker, 2013).

The youth participants in this study also stated that they built meaningful relationships with their peers and health educators. The participants described various aspects of the program that helped them develop close relationships, including team-building activities, frequent conversations about sensitive topics in a safe environment, and health educators that were relatable, informal, and non-judgmental. This finding mirrors previous research in which youth view themselves as a collective group by sharing personal experiences during group conversations (Pearce \& Larson, 2006). In addition, Strobel, Kirshner, O'Donoghue, \& McLaughlin (2008) found that supportive and more casual relationships with program staff members were critical for promoting continued program participation.

Finally, the L.O.F.T.Y. Crew members felt prepared to organize and execute various communitybased projects. Many participants expressed that the program facilitated their competence by providing opportunities to practice skills through role-playing and executing community events. Research has shown that participating in programs can develop youth competence, and that 


\section{Engagement in a Youth Leadership Council}

these experiences often lead to increased program engagement, as the youth find enjoyment in the activities (e.g., Pearce \& Larson, 2006).

\section{Limitations}

This study has several strengths. To our knowledge, this is the first study that has examined psychological needs fulfillment in a sexual health-focused YLC. It is important to explore youth engagement in a variety of program contexts. This study provided a unique opportunity to qualitatively explore the program components that contribute to high levels of engagement in a sexual health-focused YLC. We used a theory-based qualitative research approach that allowed us to explore a nuanced account of autonomy, relatedness, and competence in a predominately African-American YLC.

Further, because the youth were highly engaged in the program, we were able to recruit many current and former L.O.F.T.Y. Crew members. Our participants ranged from current L.O.F.T.Y. Crew members to some who had participated three years prior. This gave us a wide range of perspectives from which to explore engagement.

There are some important considerations to bear in mind while interpreting the findings. These considerations include external motivating factors and the selection of council participants. L.O.F.T.Y. Crew participants received material incentives, including $\$ 50$ per council meeting and hot meals at each council meeting. While this study provided strong evidence that the program components contributed to enhanced engagement by supporting autonomy, relatedness, and competence, L.O.F.T.Y. Crew participants may have been motivated by these external rewards as well. It is plausible that these incentives served to encourage youth to join the council, while the program components provided a rich experience that led to intrinsic motivation. Moreover, it is possible that there is an optimal level of incentives which, although they serve as extrinsic rewards, do not override the role of needs fulfillment. Indeed, there is evidence that external rewards (e.g., monetary incentives) may not increase youth's sense of engagement in extracurricular programs (Kuperminc, Smith, \& Henrich, 2013). Further research is necessary to assess the relative contribution of external rewards and needs fulfillment in fostering sustained engagement within youth development programs.

Another consideration is the selection process for the council. L.O.F.T.Y. Crew participants voluntarily applied and were selected to participate. The health educators accepted those who exhibited leadership skills, teamwork, and commitment to the goals of the council. Therefore, 


\section{Engagement in a Youth Leadership Council}

these youth may have already had certain characteristics that allowed them to contribute to the program in ways that enhanced or facilitated their own engagement. In this way, the process of needs fulfillment might be better classified as a dynamic exchange wherein individuals with certain skills are better able to recognize and take advantage of program components that facilitate autonomy, relatedness, and competence. Future research in this area should examine the relations among individual characteristics (e.g., social competence), program components, and needs fulfillment.

\section{Conclusions}

The results of this study indicate that L.O.F.T.Y. Crew participants perceived that the council fulfilled their psychological needs for relatedness, competence, and autonomy. According to self-determination theory, when a program fulfills these three psychological needs, youth are most likely to be engaged and to adopt program goals (i.e., to be self-motivated). Youth reported being deeply engaged and seemed to participate out of an intrinsic desire to remain engaged rather than out of compulsion.

Most importantly, youth reported an adoption of the program values. Throughout the focus groups, youth described their engagement in risk-reduction education beyond the context of the L.O.F.T.Y. Crew. Youth described providing education to their peers and family members (e.g., siblings, parents, etc.). One former L.O.F.T.Y Crew member described how he continued to educate peers even while he was in college. This extended impact speaks to the importance of youth engagement.

How can we translate theory into action? How can practitioners replicate these results with their participants? Weaving self-determination theory with the voices of this study's participants, practitioners can implement the following four action items to encourage active and sustained youth engagement:

1. Provide participants with content knowledge and skills coupled with relevant opportunities to apply and share this knowledge to build a sense of competence

2. Utilize facilitators/staff that can relate to youth in an open, non-judgmental way to build connectedness with staff

3. Have staff facilitate a safe space and engage youth in deep, honest dialogue in an open environment to facilitate connectedness with peers 


\section{Engagement in a Youth Leadership Council}

4. Give youth the power to create. Using a collaborative method, allow youth to conceive, plan, and execute activities and projects of their own choosing, providing an opportunity to build a sense of autonomy

Although implementing these action items takes careful consideration, the potential for sustained youth engagement is well worth it.

\section{References}

Bohnert, A., Fredricks, J., \& Randall, E. (2010). Capturing unique dimensions of youth organized activity involvement: Theoretical and methodological considerations. Review of Educational Research, 80(4), 576-610. https://doi.org/10.3102/0034654310364533

Felmet, K. (2014). Cool Girls, Inc. and psychological need satisfaction in female pre and early adolescents. (Unpublished master's thesis). Georgia State University, Atlanta, GA.

Hsieh, H. F., \& Shannon, S. E. (2005). Three approaches to qualitative content analysis. Qualitative Health Research, 15(9), 1277-1288. https://doi.org/10.1177/1049732305276687

Kuperminc, G. P., Smith, E. P., \& Henrich, C. C. (2013). Introduction to the special issue on "Social and motivational processes in after-school settings: Bridging gaps between theory, research, and practice." The Journal of Early Adolescence, 33(1), 5-16. https://doi.org/10.1177/0272431612469055

Mahoney, J. L., Parente, M. E., \& Lord, H. (2007). After-school program engagement: Links to child competence and program quality and content. The Elementary School Journal, 1074), 385-404. https://doi.org/10.1086/516670

Matthews, H. (2001). Citizenship, youth councils and young people's participation. Journal of Youth Studies, 4(3), 299-318. https://doi.org/10.1080/13676260120075464

Ntoumanis, N. (2005). A prospective study of participation in optional school physical education using a self-determination theory framework. Journal of Educational Psychology, 973), 444-453. https://doi.org/10.1037/0022-0663.97.3.444

Pearce, N. J., \& Larson, R. W. (2006). How teens become engaged in youth development programs: The process of motivational change in a civic activism organization. Applied Developmental Science, 10(3), 121-131. https://doi.org/10.1207/s1532480xads1003_2

Ryan, R. M., \& Deci, E. L. (2000). Self-determination theory and the facilitation of intrinsic motivation, social development, and well-being. American Psychologist, 55(1), 68-78. https://doi.org/10.1037/0003-066X.55.1.68 


\section{Engagement in a Youth Leadership Council}

Shernoff, D. J. (2010). Engagement in after-school programs as a predictor of social competence and academic performance. American Journal of Community Psychology, 45(3-4), 325-337. https://doi.org/10.1007/s10464-010-9314-0

Sikkema, K. J., Anderson, E. S., Kelly, J. A., Winett, R. A., Gore-Felton, C., Roffman, R. A., ... Brondino, M. J. (2005). Outcomes of a randomized, controlled community-level HIV prevention intervention for adolescents in low-income housing developments. AIDS, 19(14), 1509-1516. https://doi.org/10.1097/01.aids.0000183128.39701.34

Strobel, K., Kirshner, B., O'Donoghue, J., \& McLaughlin, M. (2008). Qualities that attract urban youth to after-school settings and promote continued participation. Teachers College Record, 110(8), 1677-1705.

Ward, S., \& Parker, M. (2013). The voice of youth: atmosphere in positive youth development program. Physical Education and Sport Pedagogy, 18(5), 534-548. https://doi.org/10.1080/17408989.2012.726974 